\title{
Archaeological safety considerations on construction sites
}

\author{
E. S. Patterson \\ Alexander \& Schmidt, USA
}

\begin{abstract}
When archaeological remains are uncovered due to construction operations, construction workers, archaeologists, Cultural Resource Management (CRM) personnel and even the general public are potentially exposed to additional hazards. This paper reports on specific hazards and their causes associated with archaeological excavations and other exposures on construction sites. Various protective measures for archaeological work are reviewed to help ensure safe operations on construction sites.

Keywords: safety, risk management, archaeology, construction, job sites, risk assessment, cultural resource management.
\end{abstract}

\section{Introduction}

Archaeologists are often called in when archaeological remains are unexpectedly discovered at construction sites. While traditional archaeological health concerns on excavations have included, poison ivy, sunburn, and insect bites (Joukowsky [1]), new light is being shed on infectious diseases, radioactive and chemical contaminants, and volatile explosives. Bacterial and viral infections lie in soil, along with parasites, waiting for potential new hosts. Uncovered mortal remains of individuals may still contain the pathogens that killed them, lying dormant and waiting for a vulnerable modern human population. Bullets, bombs, and mines for age-old conflicts may still pose a viable threat. Toxic wastes and hazardous substances that are improperly disposed of also pose serious health risks to archaeologists who find themselves on urban, or rural, construction job sites. 


\section{Pre-planning for safety}

Contractors are accustomed to pre-planning for construction operations. This same approach to pre-planning for phases of work can be applied to safety throughout the job.

Pre-planning for safety involves reviewing an operation or phase of work, breaking the process down into individual tasks, analysing the safety hazards associated with the task, and listing controls that will eliminate or reduce the exposure. This process presents a proactive approach to safety efforts rather than a reactive one as the result of a serious accident.

Construction firms must plan their work in order to be profitable. Safety is as important to completing the project as planning staffing, materials, and equipment (Liberty Mutual [2]). Construction site accidents cost big dollars, much of which are indirect costs and are not insurable. Conservatively, the indirect cost of accidents are often four to five times the direct, insurable costs of accidents such as lost wages, medical treatment, and damage to materials or equipment. These savings from pre-planning can be money used to offset the safety costs of a project.

Pre-planning begins with fact-finding. The specifications, drawings, and job schedule can be used to select the operation to plan. The hazards can then be brainstormed for the operation. People can use their own experiences with past accidents from similar jobs or trades. Once the exposures have been identified, it is comparatively easy to brainstorm controls to eliminate or reduce the hazard. The difficulty arises when the controls are unreasonable. Controls must be sensible, sound, practical, judicious, reasonable, and prudent. Above all, planned controls must conform to established standards, or at a minimum, best safety engineering practices. Prevention of accidents is a noble and commendable achievement but it must be balanced with the job schedule, costs, and impact on the subcontractors.

Pre-planning pays dividends in reducing hazards to both site workers and the general public. As the pre-planning process is used, old plans become valuable reference tools on future jobs for estimating, planning, and installation.

\section{Types of hazards/controls}

\subsection{Trench/excavation hazards/controls}

\subsubsection{Fatal cave in-injuries}

Excavations are one of the most dangerous places in construction work. According to the U.S. Occupational Safety \& Health Administration (OSHA), every year in the U.S., there are an estimated 75-200 deaths and more than 1,000 lost days per year due to trench cave-ins. 


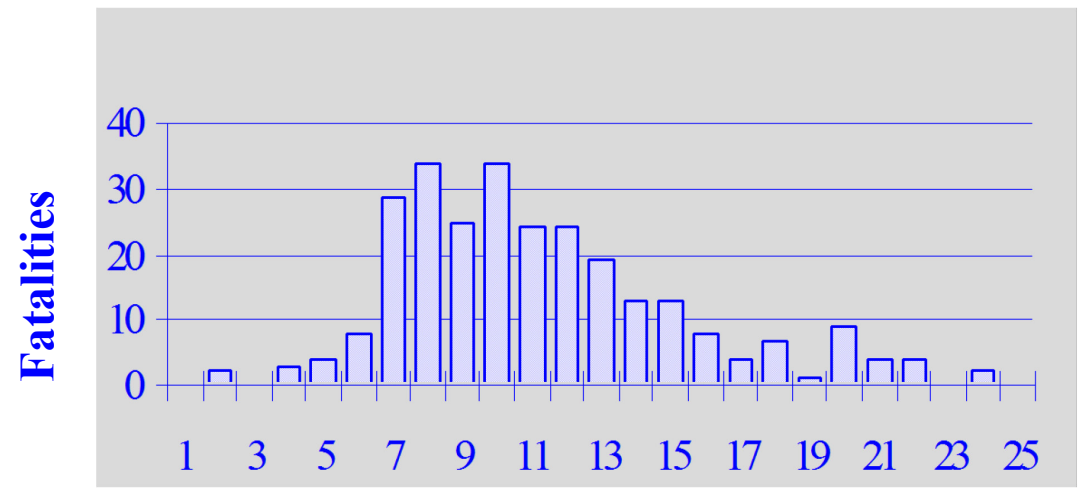

Depth (Ft)

Figure 1: $\quad$ Fatal cave-ins by trench depth. Source: U.S. OSHA.

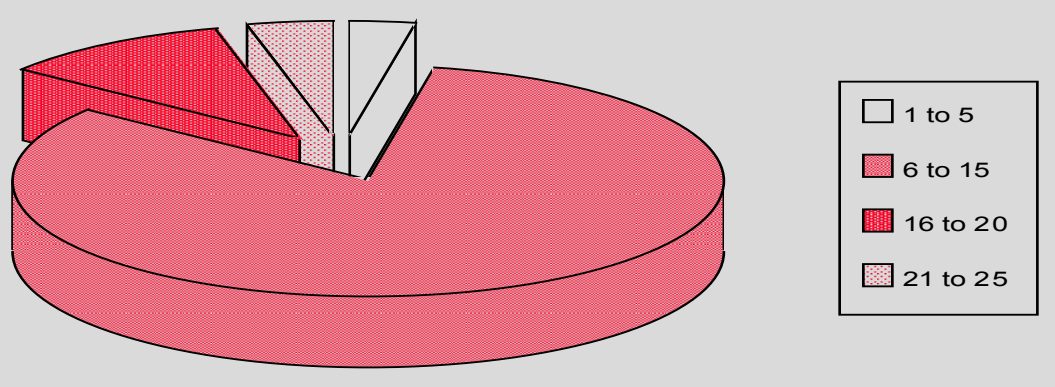

Figure 2: $\quad$ Fatal cave-ins by trench depth pie chart. Source: U.S. OSHA.

\subsubsection{Excavations and trenching}

OSHA's excavation rules apply to all open excavations made in the earth's surface including trenches. The regulation is in the construction standards at $\S 1926.650-.652$ OSHA [3] and covers:

- $\quad$ Scope and application - the rule applies to all open excavations made in the earth's surface. Excavations are defined to include trenches.

- Specific excavation requirements - to include surface hazards, underground utilities, getting in and out of the excavation, traffic hazards, hazardous atmospheres, emergency rescue, inspections, and fall protection.

- Requirements for protective systems - the rule says each employee in an excavation must be protected from cave-ins by an adequate protective system designed in accordance with the OSHA regulations for sloping and benching systems, or support, shield, and other protective systems. Exceptions would be made when: 
- Excavations are made entirely in stable rock; or

- Excavations are less than five feet deep and examination of the ground by a competent person provides no indication of a potential cave-in.

A trench is defined as any narrow excavation deeper than it is wide, and no wider than 15 feet $(4.57 \mathrm{~m})$.

Hazards associated with excavations and trenches include cave-ins and ground slides and unguarded contact with utility lines. All of these hazards can result in worker injuries, injuries to pedestrians and the general public, damage to artefacts, and property damage.

Cave-in exposures include vibration, weight, water, and soil composition.

\subsubsection{Vibration}

Vibration may be caused from heavy equipment or from street traffic. Moving heavy equipment may include bulldozers, backhoes, loaders, and/or dump trucks.

Controls for vibration include adding more space, removing the spoil pile, and closing additional traffic lanes. Haul roads can be kept at a safe distance and underpinning can be provided as needed.

Construction workers and archaeologists need to be protected from loose rocks and soil. Controls can include scaling to remove loose material, installation of protective barricades or the equivalent, and placing materials and equipment at least two feet $(0.60 \mathrm{~m})$ from the trench edge, or using retaining devices.

\subsubsection{Weight}

Weight is a major factor. Equipment and materials may collapse trench walls if operated or stored too close to the trench edge. Weight from the spoil bank can exert excessive pressure on trench walls. The spoil bank should be kept at least two feet from the trench edge.

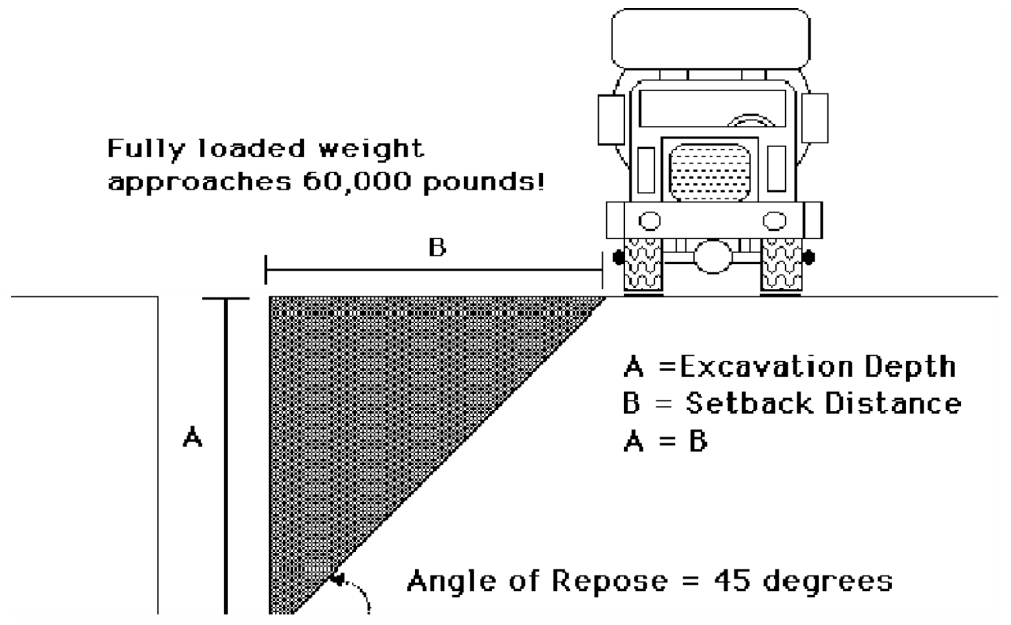

Figure 3: $\quad$ Effect of weight on trench wall integrity (Liberty Mutual [4]). 


\subsubsection{Water and temperature changes}

Water can pose a serious threat to excavations and trenches. Sources of water on job sites include surface water, the level of the water table, moisture content, rain, and cities with existing utilities in the right-of-way. Temperature changes and water content are a factor. Frozen soil does not replace appropriate shoring. Frozen soil is usually stable but the unfrozen soil below the frost line will be less cohesive. Freezing may expand the earth behind the shoring or piled near the edge of the trench, causing pressure on trench walls.

Thawing can cause mud slides and trench cave-ins or let heavy equipment slide or topple into the excavation. Dry soils tend to crack and cause trench walls to collapse.

Water can be controlled by diversion ditches, or dikes should be used to prevent surface water from entering an excavation. A good drainage system, such as a pump, will keep water from collecting in the bottom of the trench.

\subsubsection{Soil composition}

The texture of the soil is the key to its stability or cohesion. The more cohesive earth is, the more it sticks together rather than crumbles. Loose grain or sandy soil will slide back into the trench, due to lack of cohesion. Solid rock, shale, or cemented sand and gravel have great cohesion. However, if the consistency of the soil changes, there is a hazard.

\subsubsection{Trench protection}

Any trench more than five feet deep $(1.52 \mathrm{~m})$ must be protected. Trench depth is equal to the depth of the trench plus the height of the spoil pile. The trench must be protected if less than five feet deep $(1.52 \mathrm{~m})$ if the soil is unstable. A trench can be protected by the maximum allowable slope, or shoring, or a trench shield.

The maximum allowable slope is the angle at which the earth will lie without moving. This includes the evaluation of many conditions including the potential for vibration, weights, composition of the soil, anticipated changes due to water, and the depth of the cut. Slopes may include a simple slope cut, or a multiple bench cut. If sloping is not possible, then shoring or a trench shield must be provided (BAJR [5]].

Means of egress from the trench must be provided within 25 feet $(7.62 \mathrm{~m})$ of workers. Ladders must also extend three feet $(0.91 \mathrm{~m})$ above the landing at the top of the trench. Metal ladders should be used with caution around utilities.

Excavations should be inspected daily for possible cave-ins, failure of protective systems, hazardous atmospheres, and other hazardous conditions.

\subsection{Hazardous atmospheres}

Hazardous atmospheres pose very serious hazards to human health. Atmospheres may be explosive, flammable, poisonous or corrosive. Atmospheres must be tested when four feet $(1.21 \mathrm{~m})$ or deeper. In addition, testing must be performed if a competent person has reason to suspect one of the following conditions:

- Oxygen deficiency

- Accumulation of toxic gases

- Flammable atmosphere. 


\subsection{Biological hazards/controls}

Archaeologists must always practice good field safety measures that conform to current health and safety best practices. Their resulting exposure to hazardous conditions may result in significant health, safety, economic and legal consequences. Precautions that can be taken include proper dress to prevent bites and routine end-of-day body examinations for ectoparasites such as ticks and leeches. Safe sleeping and resting areas, screened or netted, are essential in areas where malaria is prevalent.

\subsubsection{Tick-borne disorders}

Tick-borne disorders include Lyme Disease, Babesiosis, Colorado Tick Fever, Ehrlichiosis, Relapsing Fever, Rocky Mountain Spotted Fever, Tick Paralysis, and Tularemia (Rabbit Fever).

\subsubsection{Rabies}

Rabies is transmitted through bite or contact between the saliva of a dead animal and an open wound. Common carriers of rabies include raccoons, skunks, foxes, bats, coyotes, and domestic dogs and cats.

\subsubsection{Fungi}

Construction workers and archaeologists may be exposed to fungi due to inhalation of airborne spores of the soil-dwelling fungi. Specific diseases include Coccidiodomycosis (Valley Fever), Histoplasmosis (bird and bat excrement), and Cryptococcosis (pigeon droppings and nests).

\subsubsection{Other biological hazards}

Other biological hazards include Hantavirus, Plague, Anthrax, Tetanus, Smallpox, Cholera, and parasites.

\subsection{Unexploded ordnance (UXO)}

You do not have to be working at a modern (or earlier) military base to encounter unexploded ordnance, also referred to as "UXO". Continued digging, mechanical or by hand, can be very dangerous. The advice of "leave it alone, and it won't go off" is not necessarily true. Some fusing systems prior to 1943 automatically create their own magnetic field that, if interrupted, will trigger detonation (Poirier and Feder [6]). Even simple vibration or movement can trigger an explosion. Radio transmitters or even cell phones may spark some munitions detonation systems.

Any nearby equipment or machinery should be halted immediately upon discovery of UXO. Everyone should be kept away from the immediate vicinity and the appropriate authorities contacted. Barricades should be erected, and fencing used, if available. If fencing is not available, barricades should be improvised including the use of ropes, flags, boards, or brush. 
The basic rules must be followed when unexploded ordnance is found: leave it alone, keep others away, and call in the local experts. Depending on the location of the job site, be prepared for the discovery of unexploded ordnance.

\subsection{Site inspections/site security}

As mentioned previously, all trenches and excavations should be inspected daily. In addition, the entire site needs to be inspected. Warning signs should be posted, using universal symbols, and multiple languages, as appropriate. The site should be secured not only to protect site workers, but also to protect the general public from exposures associated with construction operations.

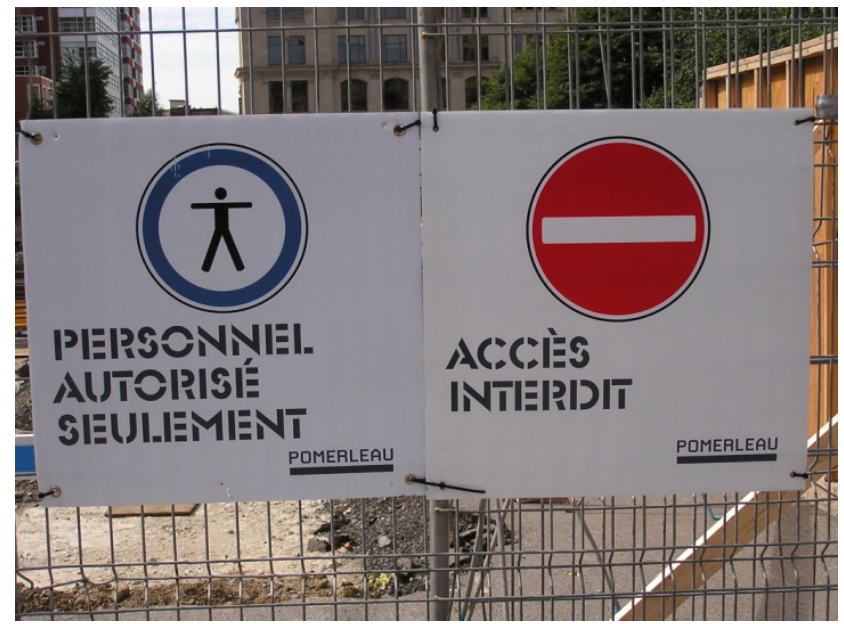

Figure 4: $\quad$ Signs limiting job site access.

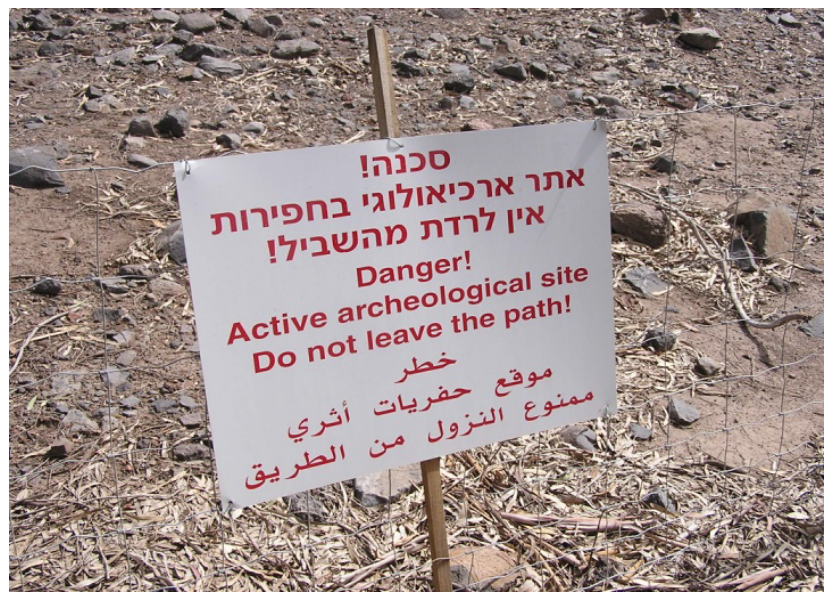

Figure 5: Warning sign in Hebrew, English, and Arabic. 
Job site security may need to be enhanced over regular site protection measures. The presence of outside archaeologists/cultural resources management personnel pose new exposures for the construction managers. In addition, there is an increased need to maintain security due to dig site excavations. Protection must be provided for artefacts in situ (still in the ground, but exposed). For archaeologists, an artefact being in situ is critical to the interpretation of that artefact and, consequently, of the culture which created it. Serious consideration must also be given to those artefacts that have been excavated and temporarily stored on-site.

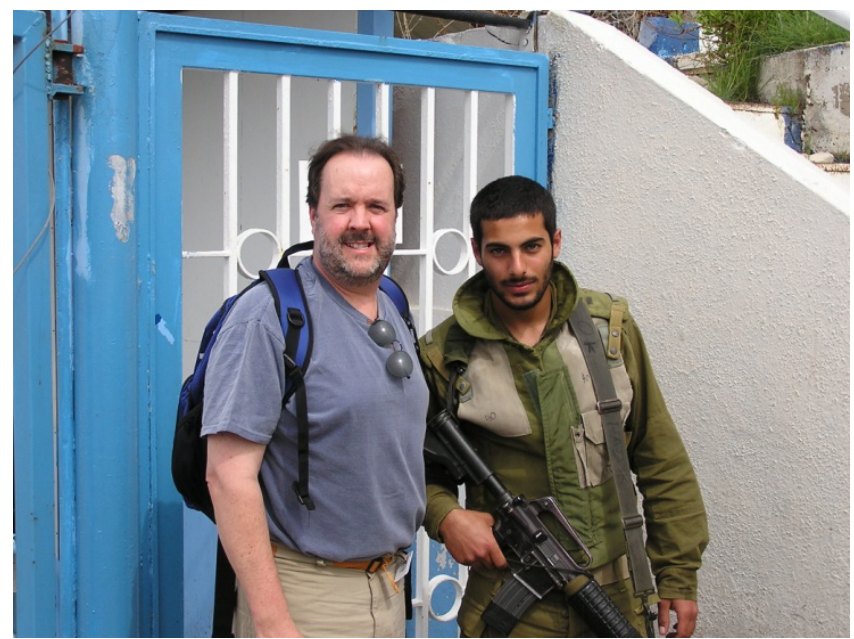

Figure 6: The author in Israel with IDF guard.

\section{Conclusion}

Excavations are among the most dangerous places in construction work. In addition to the numerous dangers from construction operations, many unrecognized hazards may exist in the same dirt which harbours valuable artefacts. Archaeologists contracted to work on construction projects need to thoroughly investigate the prior-land use histories of the job sites where they will excavate. A risk assessment, which identifies dormant and active hazards, along with recommendations for plan to control these hazards and exposures, must be a priority. All archaeologists and construction workers on the site must be educated about the potential health and safety hazards on the job site. They need to be briefed on the reasonable precautions that are to be taken to ensure the safest possible project that will result in no illnesses, injuries, delays, insurance claims, or damage to artefacts and guarantee a profitable experience for all involved. 


\section{References}

[1] Joukowsky, M., A Complete Manual of Field Archaeology, Prentice Hall Press, pp. 132-134, 1986.

[2] Liberty Mutual Insurance, Pre-Operations Safety Planning, Loss Prevention Reference Note, pp. 1, 3, 1999.

[3] U.S. Dept. of Labour, 29 CFR, Part 1926, Safety \& Health Regulations for Construction, Occupational Safety \& Health Administration (OSHA).

[4] Liberty Mutual Insurance, Trenching Safety Training Workshop, pp. 2-3, Loss Prevention, 1997.

[5] British Archaeological Jobs Resource, Basic Health and Safety Advice for Archaeology, www.bajr.org.

[6] Poirier, D. and Feder, K., Dangerous Places, Health Safety and Archaeology, Bergin \& Garvey, pp. 113-121, 173-174, 2001.

[7] Patterson, E. (Photographer). 2012. Signs limiting job site access. (Photograph).

[8] Patterson, E. (Photographer). 2009. Warning sign in Hebrew, English, and Arabic. (Photograph).

[9] Patterson, E. (Photographer). 2009. The author in Israel with IDF guard. (Photograph). 